\title{
SPECTROPHOTOMETRIC METHODS FOR THE MICRODETERMINATION OF OXYTETRACYCLINE AND HOSTACYCLINE
}

\author{
*PRASAD, A. R. G 1 \& \& RAO, V. S. ${ }^{2}$ \\ 1Department of Chemistry, Icfai University, Dehradun, U.K. India. \\ ${ }^{2}$ Department of Chemistry, S.K. University, Anantapur, A.P. India. \\ *guruprasadar@yahoo.co.in
}

\begin{abstract}
New, rapid and sensitive spectrophotometric methods have been developed for the determination of Oxytetracycline (OTC) and Hostacycline (HTC). The procedure is based on the observation that, OTC or HTC forms colored complexes with Zirconium (IV), the absorbance of which is proportional to the amount of tetracycline present. The variables affecting development of the color have been investigated and the conditions are optimized. Beer's law is obeyed in the range $1.0-33.5 \mu \mathrm{g} / \mathrm{ml}$ for OTC and 4.0-40.0 $\mathrm{\mu g} / \mathrm{ml}$ for HTC. The proposed methods can be employed for the analytical determination of Zirconium (IV). The corresponding Beer's law ranges are $0.2-6.1 \mu \mathrm{g} / \mathrm{ml}$ with OTC and 0.5-7.3 $\mu \mathrm{g} / \mathrm{ml}$ with HTC. Stoicheiometry of the complexes, regression parameters and relative standard deviation are reported for each of these determinations. The methods are successfully applied for the determination of OTC and HTC in pharmaceutical formulations and urine.
\end{abstract}

Key words: Spectrophotometric determination, oxytetracycline, hostacycline, zirconium (IV).

\section{INTRODUCTION}

Tetracyclines possess a wide range of antimicrobial activity against gram-positive and gram-negative bacteria. They have been used widely in human medicine and as additive in animal feed. Despite the development of new antibiotics, tetracyclines are still used widely in both human and veterinary medicine (Williams \& Thomas, 2002). Several methods reported in the literature for the determination of tetracyclines are expensive, time consuming and are not useful for the routine analysis (Oungpipat et al., 1995; Delepee et al., 2000; Zheng et al., 2001; Zhu et al., 2001; Cinquina et al., 2003; Delepee \& Pouliquen, 2003; Charoenraks et al., 2005; Yan et al., 2006; Rufino et al., 2009).

UV-Visible spectrophotometry is still considered to be a convenient and low cost method for the analytical determination of tetracyclines in pharmaceuticals formulations. A number of spectrophotometric and colorimetric procedures for the determination of tetracyclines in bulk material and dosage forms are reported in the literature (Abdel \& Mahrous, 1983; Suha, 1989; Emara et al.,

1991; Fernandez et al., 2002). Many such procedures are reported from these laboratories (Suryanarayana \& Rama, 1993; Basanti et al., 1996; Siva et al., 1996). The present methods report simple and accurate methods for the determination of OTC and HTC.

\section{MATERIALS AND METHODS}

Apparatus: Spectral measurements are performed on an Elico SL UV-Visible spectrophotometer. The $\mathrm{pH}$ measurements were made using an Elico $\mathrm{pH}$ meter.

Preparation of solutions: Double distilled water is employed for the preparation of solutions All chemicals and reagents used for these studies are analytical grade obtained from Merck. The hydrochlorides of tetracyclines are obtained from Sigma.

The standard solutions of tetracyclines were prepared in double distilled water and are protected from direct light throughout the analysis, because of the photosensitivity of tetracyclines to light.

Recommended procedure: Known aliquots of the buffer solution of required $\mathrm{pH}$, zirconium (IV) solution and tetracycline solution were pipetted into $25 \mathrm{ml}$ standard flask. The contents of the flask is made up to the mark with double distilled water and shaken well for uniform concentration. The absorption spectra are recorded against the respective blank solution.

\section{RESULTS}

Effect of pH: Absorption spectral characteristics were studied in the $\mathrm{pH}$ range 1 to 8 and the absorption spectrum of the complex recorded in the range 350 to $700 \mathrm{~nm}$. The OTC-Zr (IV) complex exhibits maximum absorbance at $413.6 \mathrm{~nm}$ at $\mathrm{pH} 3$ (Fig. 1) and those corresponding to HTC-Zr (IV) complex are $404 \mathrm{~nm}$ at pH 4 (Fig. 2).

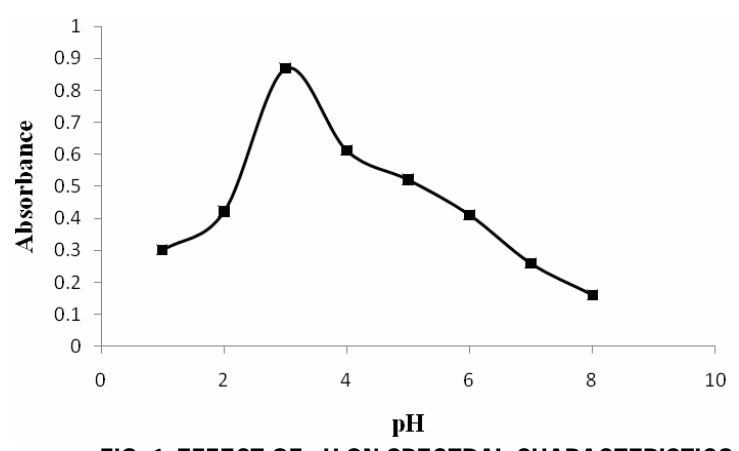

FIG. 1. EFFECT OF $\mathrm{pH}$ ON SPECTRAL CHARACTERISTICS $[\mathrm{Zr}(\mathrm{IV})]=5.5 \times 10^{-5} \mathrm{M} ;[\mathrm{OTC}]=30 \mu \mathrm{g} / \mathrm{ml} ; \lambda_{\max }=413.6 \mathrm{~nm}$.

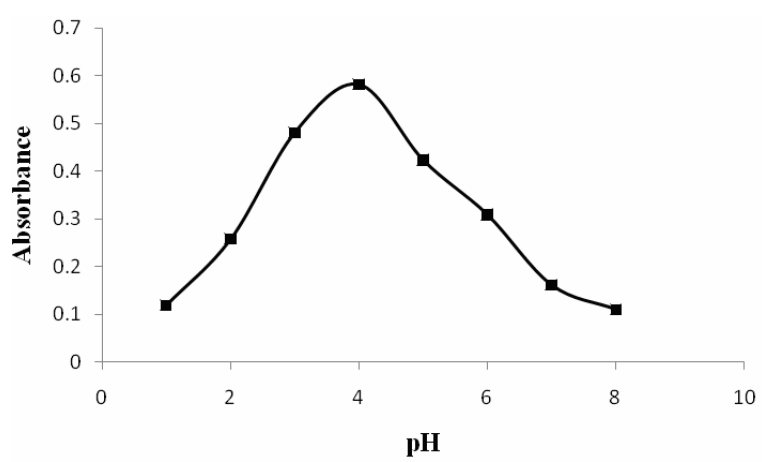

FIG. 2. EFFECT OF $\mathrm{pH}$ ON SPECTRAL CHARACTERISTICS $[\mathrm{Zr}(\mathrm{IV})]=6.6 \times 10^{-5} \mathrm{M} ;[\mathrm{HTC}]=35 \mu \mathrm{g} / \mathrm{ml} ; \lambda_{\max }=404.0 \mathrm{~nm}$ 
Effect of Time: The absorbance values of the complex solution are recorded over a period of two hours at regular intervals of time. The absorbance values are found to be approximately constant indicating that the complex formed is quiet stable over a period of $2 \mathrm{hrs}$.

Composition of the complex: The complex solution exhibits an intense yellow color in the case of OTC and an orange yellow color in the case of HTC. The author conducted Job's Method of continuous variation to determine the stoicheiometric ratio of tetracycline to zirconium (IV). The corresponding Job's curves are shown in the Figs. 3 and 4 for OTC and HTC respectively.

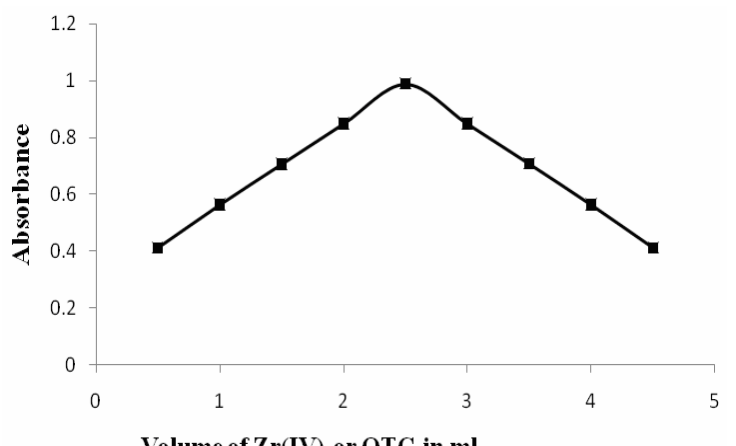

Fig. 3. DETERMINATION OF COMPOSITION OF OTC-Zr(IV) COMPLEX BY JOB'S METHOD $\mathrm{pH}=3$; [OTC] $=6.67 \times 10^{-4} \mathrm{M}$; $[\mathrm{Zr}(\mathrm{IV})]=6.67 \times 10^{-4} \mathrm{M} ; \lambda_{\text {max }}=413.6 \mathrm{~nm}$

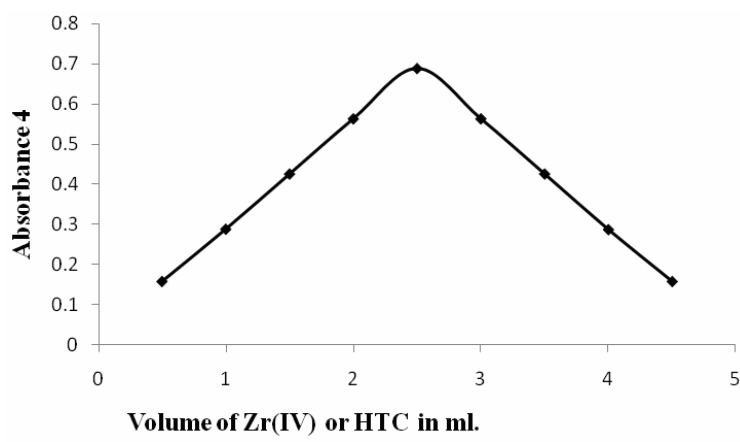

Fig. 4. DETERMINATION OF COMPOSITION OF HTC-Zr(IV) COMPLEX BY JOB'S METHOD $\mathrm{pH}=4$; [HTC] $=8 \times 10^{-4} \mathrm{M}$; $[\mathrm{Zr}(\mathrm{IV})]=8 \times 10^{-4} \mathrm{M} ; \lambda_{\max }=404.0 \mathrm{~nm}$

Metal ion concentration: The concentration of the drug was maintained constant. Studies relating to the effect of metal ion concentration were carried out by varying the $\mathrm{Zr}$ (IV) concentration. The linear calibration plots are shown in Figs. 5 and 6 respectively for OTC and HTC. The corresponding Beer's law ranges are 0.2$6.1 \mu \mathrm{g} / \mathrm{ml}$ with OTC and $0.5-7.3 \mu \mathrm{g} / \mathrm{ml}$ with HTC. The corresponding regression parameters are shown in the Table 1.

TABLE 1. REGRESSION PARAMETERS FOR EACH DETERMIONATION BY THE PROPOSED METHODS

\begin{tabular}{cccc}
\hline System & $\begin{array}{c}\text { To be } \\
\text { determined }\end{array}$ & $\begin{array}{c}\text { Regression } \\
\text { equation }\end{array}$ & $\begin{array}{c}\text { Correlation } \\
\text { coefficient }\end{array}$ \\
\hline \multirow{2}{*}{ OTC-Zr } & OTC & $y=0.021 x+0.277$ & 0.9994 \\
& Zr(IV) & $y=0.117 x+0.278$ & 0.9994 \\
\hline \multirow{2}{*}{ HTC-Zr } & HTC & $y=0.017 x+0.024$ & 0.9994 \\
& Zr(IV) & $y=0.092 x+0.023$ & 0.9994 \\
\hline
\end{tabular}

Analytical determination of OTC and HTC: Under the established optimum conditions a calibration plot was constructed by varying the concentration of the drug. The linear calibration plots shown in the Figs. 7 and 8 indicate that Beer's law is obeyed in the range of $1.0-33.5 \mu \mathrm{g} / \mathrm{ml}$ for OTC and $4.0-40.0 \mu \mathrm{g} / \mathrm{ml}$ for HTC. The pertaining regression equation and correlation coefficient are shown in the Table 1.

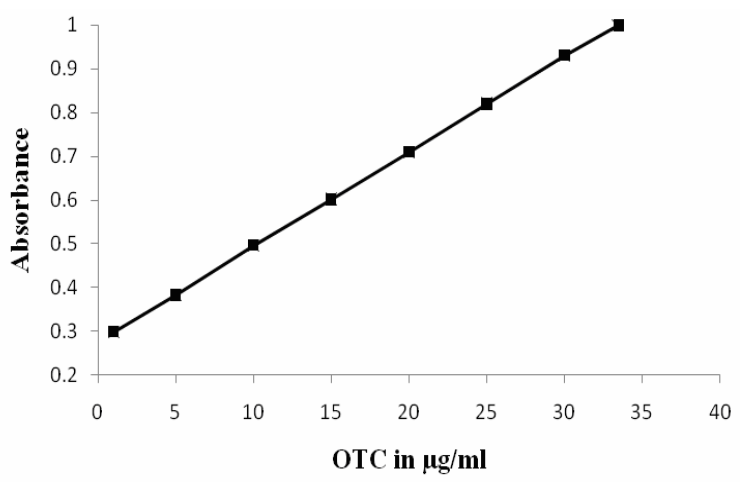

FIG. 5. EFFECT OF Zr(IV) CONCENTRATION ON ABSORBANCE $\mathrm{pH}=3 ;\left[\right.$ OTC] $=40.0 \mu \mathrm{g} / \mathrm{ml} ; \lambda_{\max }=413.6 \mathrm{~nm}$.

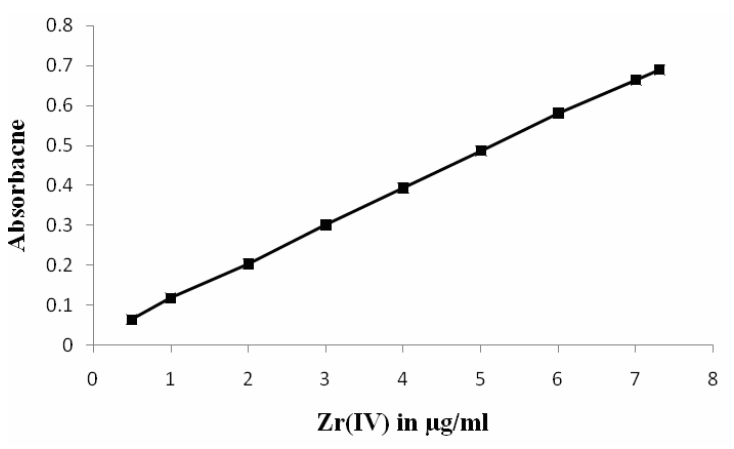

FIG. 6. EFFECT OF Zr(IV) CONCENTRATION ON ABSORBANCE $\mathrm{pH}=4 ;[\mathrm{HTC}]=50.0 \mu \mathrm{g} / \mathrm{ml} ; \lambda_{\max }=404.0 \mathrm{~nm}$.

Analytical determination of OTC and HTC: Under the established optimum conditions a calibration plot was constructed by varying the concentration of the drug. The linear calibration plots shown in the Figs. 7 and 8 indicate that Beer's law is obeyed in the range of $1.0-33.5 \mu \mathrm{g} / \mathrm{ml}$ for OTC and $4.0-40.0 \mu \mathrm{g} / \mathrm{ml}$ for HTC. The pertaining regression equation and correlation coefficient are shown in the Table 1.

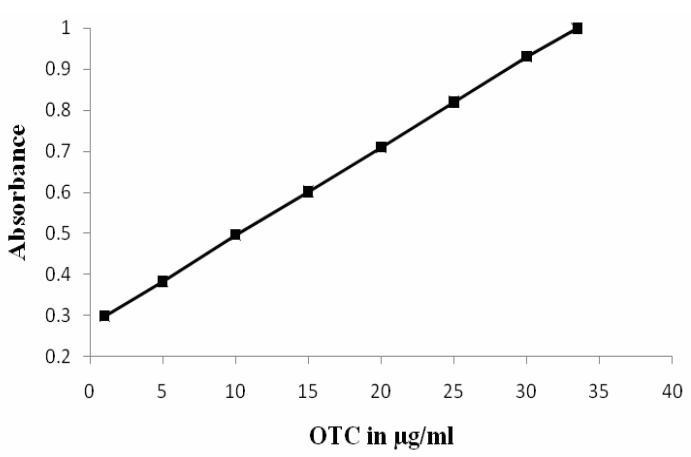

FIG. 7. ANALYTICAL DETERMINATION OF OTC $\mathrm{pH}=3 ;[\mathrm{Zr}(\mathrm{IV})]=9 \times 10^{-4} \mathrm{M} ; \lambda_{\max }=413.6 \mathrm{~nm}$ 


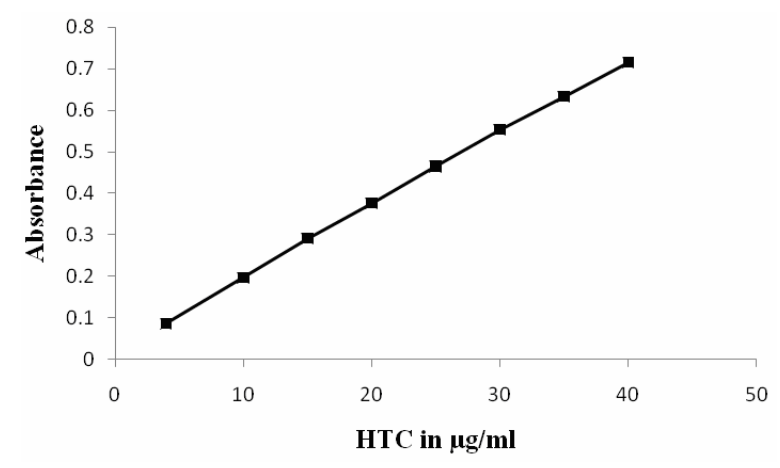

FIG. 8. ANALYTICAL DETERMINATION OF HTC $\mathrm{pH}=4 ;[\operatorname{Zr}(\mathrm{IV})]=9 \times 10^{-4} \mathrm{M} ; \lambda_{\max }=404.0 \mathrm{~nm}$.

Interference Studies: The metal ions cerium, uranium, thorium, tungsten and molybdenum seriously interfere in the determination in the concentration range of study. The metal ions lead, copper, chromium, cobalt and manganese do not interfere in the determination to the extent of 100 fold zirconium (IV) concentration. The anions fluoride, sulphate, oxalate and acetate interfere when they are present to the extent of 70 fold zirconium (IV) concentration. Common tablet excipients, such as talc, starch, lactose, magnesium stearate and gelatin were found not to interfere in the analysis.

Precision and Accuracy: The precision of the proposed methods was estimated by calculating the relative standard deviation as the average of 10 measurements. The \% RSD value is found to be 1.09 and 1.11 for OTC and HTC respectively. The accuracy of the proposed methods is reported in terms of recovery as the average of 10 measurements. The recoveries calculated (98\% to 102\%) indicate that the proposed methods are accurate.

\section{DISCUSSION}

OTC and HTC form soluble yellow colored solutions with Zr (IV). The yellow color is due to the complexation between OTC or HTC with Zr (IV).

Results reveal that $\mathrm{a} \mathrm{pH}$ of 3 and 4 is optimum for the complexation of $\mathrm{Zr}$ (IV) with of OTC and HTC respectively. The OTC or HTC - $\mathrm{Zr}(\mathrm{IV})$ complex is found to be highly stable and reproducible in these media. The media of lower $\mathrm{pH}$ are not recommended as the tetracycline (OTC or HTC) is not stable in highly acidic solutions. The absorbance values found decrease with increase in $\mathrm{pH}$ due to the possible dissociation of the complex. Similar observations are reported by Siva et al., (1996). Therefore the selected $\mathrm{pH}$ is used to determine the composition of corresponding complexes. In order to establish the stoicheiometry of the complex, the equimolar solutions of OTC or HTC and Zr (IV) are mixed in different proportions. A solution of composition 1:1 (OTC or HTC: $\mathrm{Zr}$ (IV)) has shown the maximum absorbance indicating the formation of 1:1 complex. Several studies on tetracycline-metal systems demonstrated the formation of 1:1 complex between the tetracycline and metal ion. Parashuram et al., (2007) characterized the complexes of Co (II), Ni (II) Cd (II) and inorganic Sn (II) with tetracycline by elemental analysis, vibration spectra, electronic spectra, ${ }^{1} \mathrm{H}$ NMR spectra, magnetic susceptibility measurement, thermal studies and X-ray diffraction studies. They proved that tetracyclines form 1:1 complex with these metal ions. Mahmoud et al., (1992) inferred similar observations from potentiometric studies on complexes of tetracycline and oxytetracycline with metal ions. The above mentioned literature coupled with the Job's method reported in the present article favour the formation of 1:1 complex between the OTC or HTC and Zr (IV).

Application to pharmaceutical samples: Results of analysis of OTC and HTC in different pharmaceutical formulations using the proposed method is listed in Table 2. The percentage recoveries are calculated in each case and the results are satisfactory.

TABLE 2. DETERMINATION OF OTC/HTC IN PHARMACEUTICAL SAMPLES

\begin{tabular}{|c|c|c|c|}
\hline Sample & $\begin{array}{l}\text { Labeled amount } \\
\text { mg/tab or cap }\end{array}$ & $\begin{array}{c}\text { Amount } \\
\text { found mg/tab } \\
\text { or cap }\end{array}$ & $\begin{array}{l}\text { Recove } \\
\text { ry }(\%)^{*}\end{array}$ \\
\hline \multicolumn{4}{|c|}{ Oxytetracycline } \\
\hline Terramycina ${ }^{a}$ & 250 & 255 & 102 \\
\hline Oxytetracycline ${ }^{b}$ & 50 & 49 & 98 \\
\hline \multicolumn{4}{|c|}{ Hostacycline } \\
\hline Resticlinc & 500 & 495 & 99 \\
\hline Tritetrad $^{\mathrm{d}}$ & 333 & 339 & 101.8 \\
\hline
\end{tabular}

*Average of six determinations,

a = Pfizer India Ltd., Mumbai, India,

b and $c=$ Sarabhai Chemicals Ltd., Vadodara, India

$d=$ Crips Therapeutics Pvt. Ltd., Vishakhapatnam, India

\section{TABLE 3. DETERMINATION OF HTCIOTC IN URINE}

\begin{tabular}{clll}
\hline Sample & $\begin{array}{c}\text { Added } \\
(\boldsymbol{\mu} \mathrm{g} / \mathrm{ml})\end{array}$ & $\begin{array}{c}\text { Found } \\
(\boldsymbol{\mu} \mathrm{g} / \mathrm{ml})\end{array}$ & $\begin{array}{c}\text { Recovery } \\
(\%)\end{array}$ \\
\hline Urine (1+20 dilution) + OTC & 20 & 19.8 & 99 \\
Urine (1+20 dilution) + HTC & 20 & 20.3 & 101.5 \\
\hline
\end{tabular}

Application to urine: It is found that the human body eliminates 30 to $60 \%$ of initially administered unchanged tetracyclines through urine during the first $24 \mathrm{hrs}$. OTC and HTC in urine can directly determined by employing the above methods. The results are shown in the Table 3 . A dilution of $1+20$ is performed in order to decrease the background of urine.

\section{CONCLUSION}

The proposed methods are rapid, simple and can readily be adapted for the routine analysis. The methods are found to be selective, linear $(R>0.99)$, accurate (recovery $=98$ to $102 \%)$ and precise (RSD $<1.12 \%$ ) in the respective linear concentration ranges. The method is successfully applied for the micro determination of these drugs in pharmaceutical samples and urine without any pretreatment. An additional advantage of the proposed methods is they can also be used for the analytical determination of Zirconium (IV).

\section{REFERENCES}

Abdel-Kahlek, M. M. \& Mahrous, M. S. (1983). Spectrophotometric determination of tetracyclines and cephalosporins with ammonium vanadate. Talanta, 30:792-797.

Basanti Rao, M.; Rama Murthy, P. S. \& Suryanarayana Rao, V. (1996). Determination of oxytetracycline in pharmaceutical formulations using thorium for complexation. Indian Drugs, 33:350351.

Charoenraks, T.; Chuanuwatanakul, S.; Honda, K.; Yamaguchi, Y. \& Chailapakul, O. (2005). Analysis of tetracycline antibiotics using HPLC with pulsed amperometric detection, Analytical. Sciences, 21:241-245.

Cinquina, A. L.; Longo, F.; Anastasi, G.; Giannetti, L. \& Cozzani, R. (2003). Validation of a highperformance liquid chromatography method for the determination of oxytetracycline, tetracycline, chlortetracycline and doxycycline in bovine milk and muscle. Journal of Chromatography A, 987:227-233. 
Delepee, R.; Maume, D.; Le Bizee, B. \& Pouliquen, H. (2000). Preliminary assays to elucidate the structure of oxytetracycline degradation products in sediments: Determination of natura tetracyclines by high-performance liquid chromatography-fast atom bombardment mass spectrometry. Journal of Chromatography $B$, 748:369-381

Delepee, R. \& Pouliquen, H. (2003). Ion-paired solid phase extraction as a sample preparation strategy for the highperformance liquid determination of oxytetracycline in the bryophyte Fontinalis antipyretica. Anallytica Chimica Acta 475:117-123.

Emara, K. M.; Askel, H. F. \& Saleh, G. S. (1991). Spectrophotometric determination of tetracycline and oxytetracycline in pharmaceutical preparations. Talanta, 38:12191221.

Fernandez-Gonzalez, R.; Garcia-Falcon, M. S. \& Simal-Gandra, J. (2002). Quantitative analysis for second-derivative synchronous spectrofluorimetry. Anallytica Chimica Acta, 455:143-148.

Mahmoud, A. G.; Azab, H. A.; Ahmed, H. \& Ali, M. A. (1992). Potentiometric studies on the complexes of tetracycline (TC) and oxytetracyclin (OTC) with some metal ions. Monatshefte für Chemie / Chemical Monthly, 123:51-58.

Oungpipat, W.; Alexander, P. W. \& Southwell-Keely, P. (1995). Flow injection detection of tetracyclines by electrocatalytic oxidation at a nickel-modified glassy carbon electrode. Analyst, 120:1559-1565.

Parashuram, M.; Bibhesh, K. S.; Shuchi D. \& Rakesh, K. S. (2007). Spectroscopic characterization of complexes of tetracycline with cobalt(II), nickel(II), cadmium(II) and inorganic Sn(II). Main Group Chemistry, 6(2):109-119.

Rufinio José, L.; Weinert Patrícia, L.; Pezza Helena, R. \& e Leonardo, P. (2009). Flow-injection spectrophotometric determination of tetracycline and doxycycline in pharmaceutical formulations using chloramine-T as oxidizing agent. Química Nova, 32:1764-1769.
Siva Chandra, Y.; Suryanarayana Rao, V. \& Rama Murthy, P. S. (1996). Determination of hostacycline and doxycycline using Thorium ( IV) as spectrophotometric reagent. Indian Journal of Pharaceutical Sciences, July-August:157-159.

Suha, U. (1989). Colorimetric determination of tetracycline derivatives in pharmaceutical preparations. Journal of the Association of Official Analytical Chemists, 72: 242-244.

Suryanarayana Rao, V. \& Rama Devi, B. (1993). Spectrophotometric determination tetracycline hydrochloride. Indian Drugs, 30:531-533.

Williams, D. \& Thomas, L. (2002). Foye's Principles of Medicinal Chemistry. 5th Edn., Lippincott Williams and Wilkins, Philadelphia USA., 1114.

Yan, X.; Houjiang, Z.; Zhujun, Z.; Deyong, H. \& Chao, H. (2006) Molecularly imprinted on-line solid-phase extraction combined with flow-injection chemiluminescence for the determination of tetracycline. Analyst, 7:829-834.

Zheng, X.; Mei, Y. \& Zhang, Z. (2001). Flowinjection chemiluminescence determination of tetracyclines with in situ electrogenerated bromine as the oxidant. Anallytica Chimica Acta, 440:143-149.

Zhu, J.; Snow, D. D.; Cassada, D. A. \& Monson, J. (2001). Analysis of oxytetracycline, tetracycline and chlortetracycline in water using solid-phase extraction and liquid chromatographytandem mass spectrometry. Journal of Chromatography $A$. 92:,177-18. 